\section{Annual Report to the \\ Nevada Legislature \\ and the Governor of the \\ State of Nevada}

January 30, 2005

Volume III:

Renewable Portfolio Standard Report

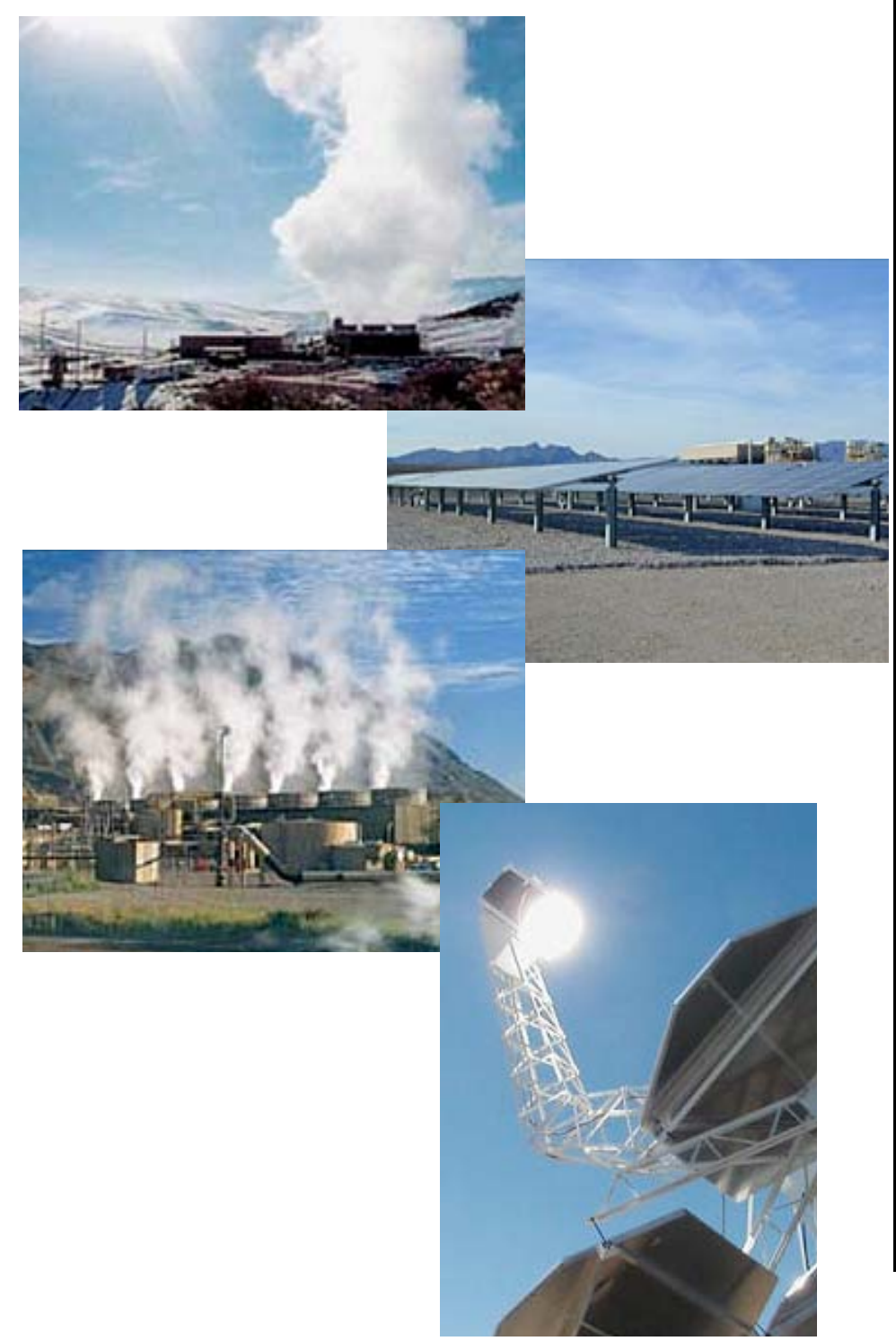

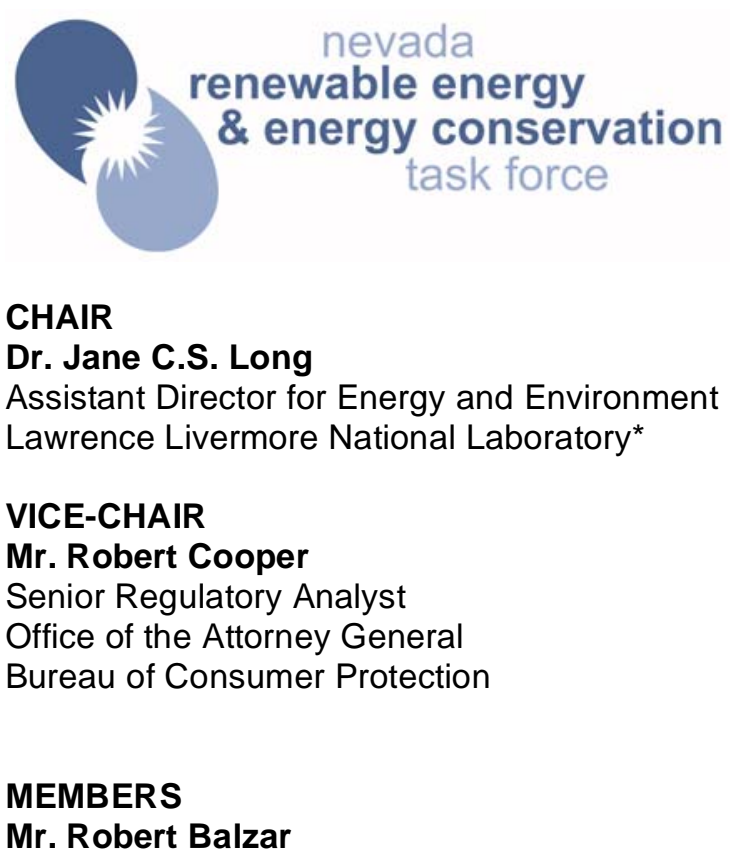

Mr. Robert Balzar

Director of Energy Efficiency and Conservation

Sierra Pacific Resources

Mr. Tim Carlson

President

Carlson and Associates

Mr. Dan Geary

Nevada Representative

The National Environmental Trust

Mr. Russ Fields

President

Nevada Mining Association

Ms. Rose McKinney-James

Founder

Energy Works Consulting LLC

Mr. Elwood Miller

Executive Coordinator

Nevada Fire Safe Council

Mr. Mark Russell

Vice President and General Counsel

The Mirage Casino-Hotel

Mr. Danny Thompson

Executive Secretary-Treasurer

Nevada State AFL-CIO

*former Director

Great Basin Center for Geothermal Energy

University of Nevada, Reno 


\title{
Summary of Recommendations: \\ Legislative and Regulatory Actions to Consider \\ For \\ Ensuring the Long-Term Effectiveness of the \\ Nevada Renewable Portfolio Standard
}

\author{
Prepared by: \\ Kevin Porter of Exeter Associates, Inc. \\ Robert Grace of Sustainable Energy Advantage LLC \\ Ryan Wiser of Ernest Orlando Berkeley National Laboratory
}

November 29, 2004 


\section{TABLE OF CONTENTS}

$\underline{\text { Page }}$

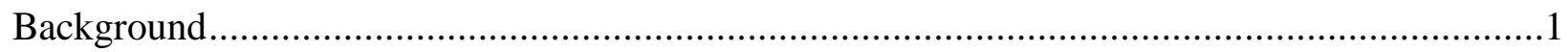

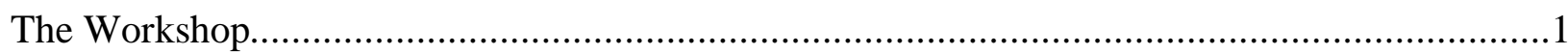

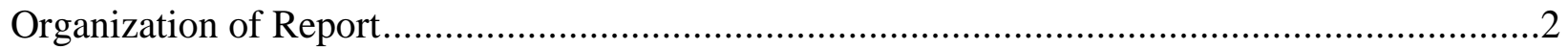

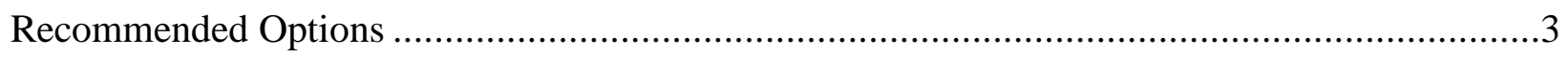

Establish Incentives Encouraging Utility Actions in Support of Nevada RPS Compliance.......3

Adopt an Alternative Compliance Mechanism (ACM) and Target ACM Funds Toward

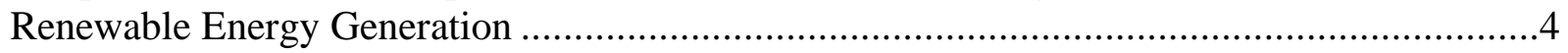

Improve Utility Renewable Energy Solicitations .................................................5

Allow Imports of Renewable Energy Generation or WREGIS Renewable Energy Credits for a Limited Percentage of the Nevada RPS .........................................................

Consider Extending the Solar PV Energy Demonstration Program ..................................8

Appendices 


\section{Background:}

In 2001, the Nevada Legislature passed an aggressive renewable portfolio standard (Nevada RPS) that called for 5\% of each major utility's resource mix to come from eligible renewable energy by 2003 , rising by $2 \%$ every two years to $15 \%$ by 2013 . Of the RPS standard, $5 \%$ per year must come from solar energy. The early performance of the Nevada RPS is generally considered to be disappointing. So far, only a small quantity of electricity statewide has been generated by new renewable energy systems. The utilities and many other stakeholders appear to agree that the utilities, which were unable to fully comply with the RPS in 2003, will continue to have difficulty complying in 2004 and 2005, and perhaps beyond.

To date, there have been several efforts to improve compliance with the RPS (such as California and New Mexico). Other states in the region are also motivated to develop their renewable resources, and some have adopted RPS policies. A workshop as held on November 4, 2004 in Reno in order to address additional measures available to strengthen the Nevada RPS, and to consider the implications and potential interaction with RPS policies in nearby states.

The purpose of this report is to identify and summarize the top policy priorities, from among those identified and discussed at the November 4, 2004 Reno Workshop, to be considered by the Nevada Renewable Energy and Energy Efficiency Task Force for implementation.

\section{The Workshop:}

On November $4^{\text {th }}$, the Nevada Renewable Energy and Energy Efficiency Task Force held a workshop on how to improve the Nevada RPS. About 60 people attended the workshop, representing a broad array of stakeholders. Presenters included the authors and Dick Burdette of the Nevada Office of Energy. Briefings were provided on the Nevada and California RPS policies, transmission issues and renewable energy in the West, and the status of the Western Renewable Energy Generation Information System (WREGIS). Participants at the workshop then engaged in a brainstorming session focused on options (primarily regulatory or legislative) to improve the Nevada RPS. Questions were posed to the participants about how to improve the Nevada RPS, and options were solicited from participants. Participants were then asked to assist in prioritizing the options identified with a show of hands. ${ }^{1}$

The list of issue areas discussed included:

- Are actions required to support the 5\% solar component of the Nevada RPS?

- What, if any, changes to enforcement or incentive mechanisms might improve the Nevada RPS?

- Would changes to utility renewable energy solicitations improve compliance?

- Are there any additional changes necessary to ensure financing of renewable energy projects? ${ }^{2}$

\footnotetext{
${ }^{1}$ The informal voting is considered indicative but not definitive, as participation was self-selected (and therefore not representative of any balanced population of stakeholders), and participants were given several "votes" per issue, depending on the number and nature of options identified.

${ }^{2}$ Beyond the Temporary Renewable Energy Development (“TRED”) mechanism already adopted.
} 
- Are expansions of Nevada RPS eligibility to other resources besides renewable resources warranted?

- Are changes to Nevada RPS renewable resource eligibility warranted?

- What policy options are available for imports of renewable energy credits?

- What options are available with the use of WREGIS?

- What policy options are available regarding transmission?

- How can, or should, future Nevada RPS targets be adjusted to account for failed contracts?

- How might the Nevada RPS better incorporate demonstration technologies?

After the workshop, the authors ranked the options in each issue area by the number of votes received from the workshop participants, and selected the top three in each issue area for further evaluation. Substantial overlap was identified among some of the options identified in response to different issue areas. The authors then reduced and consolidated the resulting list of options to what they believe are the five most promising options for achieving successful development of renewable energy generation that can be accomplished through regulation or legislation, for consideration by the Task Force.

This report does not discuss the TRED mechanism, or workshop participants thought it was working fine and did not need modification. This report also does not discuss the "T4 Wind" project, a DOE funded study conducted by the Nevada Office of Energy, as the study is still in progress and way not ready for review by the authors.

\section{Organization of Report:}

The remainder of this report discusses the five top priority policy options identified.

Appendix A lists additional options that the authors recommend as also worthy of consideration, although not meriting consideration as top priorities at this point in time.

Appendix B identifies options that the authors deemed not worthy of consideration at this time. ${ }^{3}$

Appendix C summarizes the full list of issues and options identified a the workshop, along with the associated informal prioritization voting results.

\section{Recommended Options:}

The authors identified the following five options as the current top priorities (no particular order) for consideration by the Nevada Renewable Energy and Energy Efficiency Task Force:

- Establish incentives encouraging certain utility actions in support of Nevada RPS Compliance;

\footnotetext{
3 "No action required" options were not discussed, as this is simply the status quo and no legislative or regulatory measures are involved.
} 
- Adopt an Alternative Compliance Mechanism (ACM), and target ACM funds toward renewable energy generation;

- Improve Utility renewable energy solicitations;

- Allow imports of renewable energy generation or WREGIS renewable energy credits for a limited percentage of the Nevada RPS; and

- Consider extending the Solar PV Energy Demonstration Program.

Each of these options is discussed in more detail below.

\section{Establish Incentives Encouraging Utility Actions in Support of Nevada RPS Compliance}

For a number of reasons, utility incentives are not well aligned with RPS success, and procurement failures may result in the RPS not being met.

- Presently, utilities that do not comply with the Nevada RPS can petition the Nevada PUC for a waiver. The utilities have little incentive to select renewable energy generation projects that will come on-line, and after contracting with a generator, if that generator fails to attract financing and get built, the utility has a reasonable case to make for a PUC waiver. So any project delay or failure can result in the RPS simply not being met.

- If a waiver is not granted, the Nevada PUC could impose unspecified penalties on the Nevada utilities. In essence, Nevada utilities face only negative incentives with the Nevada RPS — either comply, apply for a waiver or perhaps be penalized.

- Only if the utilities own a renewable energy project will a utility earn its standard allowed rate of return. Given the limited rate of return, utility investment incentives are strongest for the more familiar conventional transmission and distribution investments.

- In addition, the utilities have no incentive to consider renewable energy in prioritizing transmission project planning and investments.

Under this option, utilities would receive an adder to their rate of return or other financial incentive for undertaking actions supporting compliance with the Nevada RPS. Possible examples include:

- Transmission investments necessary to reach otherwise cost-effective but inaccessible renewable resources, or even renewable energy facilities themselves could be designated by the PUC as "critical facilities" (preserving these facilities as utility owned), thus providing the Nevada utilities a higher rate of return; or

- Financial incentives might for be made available in exchange for a utility conducting bidding solicitations successfully and in a timely manner; building their own renewable energy plant, purchasing output renewable energy from plants that ensure full compliance with the statute; or ratcheting up their solar rebate programs.

The Nevada PUC presumably would have to adopt regulations to provide utility incentives for compliance with the Nevada RPS. Legislation is probably not necessary. The Nevada PUC would have to exercise careful oversight and perhaps design the incentives to be achievable, but not too easily achievable. 
Implementing such incentives would lead to greater certainty of the implications of successful, and unsuccessful, RPS procurement. They would serve to align utility and public policy incentives more effectively. And they would result in renewable energy generation being getting financed and built more effectively than under the current regime. [Note: The authors believe that incentives options such as these may work most effectively in concert with implementation of the alternative compliance mechanism described below.]

\section{Adopt an Alternative Compliance Mechanism (ACM) and Target ACM Funds Toward Renewable Energy Generation}

The Nevada RPS statute gives the Nevada PUC the authority to impose a penalty on a Nevada utility for failing to comply with the Nevada RPS, unless the utility successfully seeks an RPS waiver for that year. So far, the Nevada PUC has granted all utility petitions for waivers, and has yet to impose penalties for RPS non-compliance. The Nevada PUC, however, may impose a penalty of at least the difference in price between the market price of electricity and the price of the renewable energy generation. Nevada utilities may not recover such penalties in rates or in any other way from retail customers. The resulting environment is not particularly conducive to getting renewable generation built: if the utilities contract and fail, nothing will result (the RPS is simply not met); if the utilities fail to contract, they may be painted as bad actors and subjected to penalties, even if the fault lies elsewhere for their lack of success.

Several states with RPS policies have included an alternative compliance mechanism (ACM) that can be used in lieu of procuring renewable energy generation or credits. These states include Maryland, Massachusetts, New Jersey and Rhode Island. In the event that the obligated entity falls short on meeting its annual RPS procurement targets, that obligated entity may make an ACM payment for any MWh shortfall. The ACM is generally set at a high level, sufficiently above the expected cost premium of renewable energy (such as $\$ 50 / \mathrm{MWh}$ ) to encourage compliance with the RPS, but the ACM can be paid if market circumstances warrant without a regulatory process to impose a penalty. ACM payments are typically deposited in a fund to underwrite renewable energy projects through grants, loans or production-type incentive payments. Implementation details include the level of the ACM (in \$/MWh of RPS shortfall); how ACM proceeds should be used; and who should administer funds via the ACM.

Adopting an ACM would likely require legislation. The ACM should be set high enough that RPS compliance focuses on the development of renewable energy plants. As an example, the ACM is set at \$50/MWh in Massachusetts, New Jersey, and Rhode Island. Because Nevada has two tiers for RPS compliance-one for solar and one for other renewables-Nevada should adopt a separate ACM for solar energy than for the other renewable energy technologies. Because solar is more expensive than other renewable energy technologies, the solar ACM should be higher (for example, the New Jersey solar tier ACM is set at \$300/MWh.

In concert with adopting an ACM, the waiver provisions would be eliminated as obsolete. Nevada utilities would be able to recover ACM payments so long as paying the ACM is considered to be a prudent means of RPS compliance at the time, if there are insufficient renewable energy resources available at the time; or in the event a default by the renewable 
energy generator caused under-compliance with RPS targets ${ }^{4}$. The Nevada utility making the claim for ACM cost recovery should have the burden of proof of why cost recovery is justified, and the Nevada PUC should approve reasonable petitions for ACM cost recovery.

The ACM is attractive because utility failure to comply and generator failure to deliver no longer needs to result in shortfalls in meeting RPS targets. While there may be a delay in timing of actual renewable generation, because the ACM is set above the expected cost premium for of renewable energy, chances are good that the targeted RPS volumes will ultimately be met. Finally, utilities in states with ACMs have been strong advocates of this mechanism because there is no stigma for RPS non-compliance (such as that associated with a penalty), and utilities have the opportunity for cost recovery so long as they are diligent in their efforts. In addition, the clear and measurable incentives and repercussions are amendable to analysis and decision making.

\section{Improve Utility Renewable Energy Solicitations}

So far, Sierra Pacific has conducted two renewable energy solicitations, one in 2002 and the other in 2003. While some contracts have been executed and improved, little new renewable energy generation has come on-line, and the Nevada RPS targets are not being met. A number of issues associated with the procurement process were identified as areas where changes might improve results.

Problems identified have included slow utility turnaround time in responding to proposals; speculative bidding by generators; lack of adequate distinction between projects at different stages of development and between those that are viable and those that are not; and project delays and cancellations.

Recommendations for improvements to the utility solicitation process include:

- Speeding the procurement cycle of each RFP, thereby leaving less time for circumstances to change sufficiently to alter the viability of a given bid.

- Over-procuring renewable energy capacity to ensure that enough renewable energy is available to meet the Nevada RPS requirements in the event that the utilities and selected projects fail to successfully negotiate contracts, or projects fail to gain necessary permits or attract required financing.

- Certain threshold eligibility criteria might also be considered or made more stringent for each bidding solicitation, such as requirements for documentation of site control, evidence of sufficient renewable resources, documentation of sufficient development progress, and the financial capability to move the project to completion.

- Bid security, and more stringent penalties on developers for not achieving milestones, might also improve solicitation results.

Although the Nevada utilities could implement some of these options on their own, the Nevada PUC may wish to implement RPS-specific regulations on renewable energy solicitations

\footnotetext{
${ }^{4}$ Currently there would be no repercussions for such a generator default, another factor causing the current RPS rules to be unlikely to result in RPS targets being fully met.
} 
incorporating eligibility criteria and the other issues described above. Should this option be adopted, the Nevada PUC also may want to require the Nevada utilities to make periodic status filings.

\section{Allow Imports of Renewable Energy Generation or WREGIS Renewable Energy Credits for a Limited Percentage of the Nevada RPS}

The Nevada RPS only allows out-of-state renewable energy generation if it is transmitted on a dedicated transmission line for that generator, or a line that is at most shared with one other renewable energy generator. Recently, the Nevada PUC ruled (the Canby order) that Sierra Pacific could obtain renewable energy generation that qualifies for the Nevada RPS if it is interconnected with a Sierra Pacific substation, even if that substation is not located in Nevada.

Nevada PUC regulations allow Nevada utilities to transfer renewable energy credits in order to comply with the Nevada RPS. Nevada PUC staff oversees and tracks renewable energy credit transfers between the Nevada utilities. Concurrently, the Western Governor's Association and the California Energy Commission have worked on creating a west-wide renewable energy tracking system, known as the Western Renewable Energy Generation Information System, or WREGIS.

There are reasons that states with RPS requirements may want to look to broad geographic eligibility. These include minimizing the cost of compliance by tapping renewables where their availability is greatest or their cost is lowest; minimizing local permitting or land use conflicts; bypassing transmission constraints; or achieving regional or global environmental benefits. Broader regional markets for renewable energy would result in more renewables being built at lower total cost, although the location of such generators would tend towards least-cost locations.

There are other reasons why a state might wish to adopt narrow geographic eligibility rules. These include achieving local economic development and environmental benefits. In addition, in-state generators will fare better if not exposed to competition from far-flung generators. As a result, Nevada (like other RPS states) faces an inevitable tension between wanting to encourage in-state renewable energy generation for economic development and environmental quality reasons, versus keeping barriers to out-of-state renewable energy generation sufficiently low to ensure an adequate renewable energy supply to meet RPS targets at a reasonable cost. An additional complication is the prohibition of restrictions in interstate commerce inherent in the Interstate Commerce Clause of the U.S. Constitution. In Nevada's case, experience to date suggests that the combination of the in-state restriction and the high demands of the Nevada RPS may make compliance difficult.

To balance these competing objectives, Nevada may wish to allow a limited amount of out-ofstate renewable energy generation or renewable energy credits for eligibility under the Nevada RPS. One alternative raised at the workshop that garnered significant interest was to allow up to $15 \%$ of the compliance target to be met by out-of-state generation without being limited to energy delivery to Nevada via a dedicated line. ${ }^{5}$ This would be accomplished through utility purchase of WREGIS Certificates, either with or without an accompanying import of energy into Nevada. To implement such a change, legislation would be required, stating that up to a

\footnotetext{
${ }^{5}$ This percentage is presented as a reasonable starting point for discussion purposes.
} 
specified percentage of the renewable energy credits or MWh for annual RPS compliance can derive from out-of-state renewable energy generation, subject to verification by the Nevada PUC or (if the generator is registered in WREGIS) by WREGIS.

\section{Addressing the Implications of WREGIS for Nevada}

Western states can voluntarily opt to rely on WREGIS, in whole or in part, as the basis of tracking renewable energy generation for RPS compliance or other public policy purposes. Generators can voluntarily opt to have their generation tracked in WREGIS, but if they do so, they $\underline{\text { must }}$ have all of their production tracked in WREGIS, and not in multiple tracking systems. ${ }^{6}$ Because Nevada up to now has conducted its own tracking system, Nevada would have to decide whether to (i) use WREGIS for tracking out-of-state renewable energy generation and credits and Nevada generators that register in WREGIS, or (ii) whether to use its own tracking system. Nevada cannot do both.

More importantly, renewable energy generators that may be eligible for the Nevada RPS will have to decide whether to register with WREGIS (allowing access to markets in other WECC states) or with the Nevada PUC - WREGIS will not allow renewable energy generators to register with both. ${ }^{7}$ The difficulties in achieving Nevada RPS compliance might be aggravated if generators choosing to register with WREGIS are ineligible for the Nevada RPS. Therefore, the Nevada PUC should consider renewable energy credit issues in Nevada, with options including adopting WREGIS as a sole means of tracking RECS to recognizing WREGIS Certificates as an alternative to the Nevada tracking system as a means for a utility to demonstrate compliance.

\footnotetext{
${ }^{6}$ As a result of this requirement, which must be recognized to prevent double counting, unique claims and reliable verification, future registration of a Nevada generator in WREGIS will force the Nevada PUC to consider accommodating WREGIS Certificates as an alternative means of verification for (as least) Nevada generators that opt into WREGIS.

${ }^{7}$ It is important to recognize the likelihood that, in the future, a generator may bid part of its generation into the Nevada RPS and part into other markets.
} 


\section{Addressing the Implications of the Canby Decision}

The Nevada PUC also should examine the implications of the Canby decision, either as part of a broader docket on the use of renewable energy credits in Nevada or in a separate docket just focused on the order. In theory, a Nevada utility could have out-of-state renewable energy generation feed into any substation the utility may own, regardless of where or how far away from Nevada the renewable energy generator is. In practice, the language of the Canby order resembles a slippery slope: it may be difficult to draw a bright line in any location, as to how much is enough, and how far away is too far away. As a result there may not be a current limitation on the role played by out-of-state generation. Therefore, the PUC should consider whether a clearer mechanism for allowing a limited amount of out-of-state generation to participate in the Nevada RPS, such as that suggested here, would better serve Nevada's interests. Alternatively, the PUC should consider what restrictions it will place, if any, on these Canby transactions, in order to provide more clarity to the Nevada RPS.

The benefits of adopting a recommendation for allowing a limited percentage of the Nevada RPS to be met by out-of-state resources include:

- Encouraging a more liquid western market for renewable energy. If other states follow Nevada's lead, Nevada generators may be better able to export some of its renewable energy to other states. As such, economic development and environmental benefits to Nevada may not be compromised.

- Easing the difficulties Nevada utilities have experienced so far in complying with the Nevada RPS.

- Creating an opportunity to recognize and utilize WREGIS in a way that benefits Nevada.

If such a recommendation is adopted, a critical design decision to be resolved is under what conditions the $15 \%$ could be met. Does the electricity need to be delivered to Nevada over the interstate transmission grid, or can unbundled RECs be used without requiring energy delivery to Nevada? If unbundled RECs are recognized, in what locations can generators be located? Should reciprocity requirements with other states be included? (i.e. Nevada will recognize RECs from California if California recognizes Nevada RECs without an energy delivery requirement)

\section{Consider Extending the Solar PV Energy Demonstration Program}

In 2003, the Nevada State Legislative approved AB 431, creating the Solar Energy Demonstration Program. Under AB 431, the Nevada PUC may annually consider and approve solar application for schools, other public buildings, and private residences and small businesses. To jump start the program, the Nevada PUC approved rebates of $\$ 5$ per watt beginning July 1 , 2004; \$4 per watt beginning in July 1, 2005; and \$3 per watt beginning in July 1, 2006. The rebate expires on July 1, 2007. Furthermore, under a recent stipulation, the two Nevada utilities are committed to the rebate level, for up to $500 \mathrm{~kW}$ to June 30,$2005 ; 1,500 \mathrm{~kW}$ to June 30,2006 ; and 3,000 kW to June 30, 2007. 
Nevada should consider extending the rebate for a longer period of time than three years, and making the decline in rebate levels more gradual over time. Such changes would correspond better with the long-term solar requirement of the Nevada RPS and would also recognize that it can take some time to transform the solar market. Other changes Nevada may wish to consider is to streamline the rebate application and net metering processes; making changes to the rebate application process to better accommodate large-scale home builders; require multi-year warranties for the solar systems, and to adopt performance requirements to ensure that the solar systems are working effectively. 
APPENDIX A 


\section{Appendix A - Options Considered But Not Recommended}

The options listed in this appendix ranked within the top three of each issue area, and were considered in narrowing the list of top priorities. While these options were not identified as top priorities at this time, they are still worthy of consideration by the Task Force at a later date.

\section{Require Solar in New Construction}

California Governor Schwarzenegger has proposed that a minimum proportion of new home construction must include rooftop solar panels. Such a requirement in Nevada could help the two Nevada utilities meet the solar portion of the Nevada RPS. While there is no doubt that such a mandate would help in achieving the solar portion of the RPS, extending the solar demonstration program will also help serve that need, and perhaps at less cost. It also remains somewhat unclear whether the utilities will ultimately have difficulty meeting their solar energy requirements in the mid-term. More experience with existing policies will help answer that question. Finally, the political challenge of mandating solar on new home construction should not be under-emphasized.

\section{Allocate Economic Development Bonds to Renewable Energy Development}

Nevada's economic development program includes the ability to issue bonds, and these bonds could theoretically be used to support the development of renewable energy projects. In general, however, there is stiff competition for state bonds, and it is not clear what priority renewable energy development would have. Also, using state bonds may hinder use of the federal production tax credit, as capital subsidies would reduce the value of the federal PTC by up to $50 \%$. If revenue bonds are used, the revenue bonds must be supported by a revenue stream such

as from utility power purchase contracts. Such contracts have been difficult to execute because of the Nevada utilities' difficult financial circumstances. Finally, with the passage of TRED, financing may no longer be the critical barrier to RPS achievement. For these reasons, other options were determined to be more beneficial.

\section{Expanding RPS Eligibility}

Some participants at the workshop suggested adding direct-use geothermal and combined heat and power to the list of eligible technologies for the Nevada RPS. While there may be some merit to these proposals, many technologies are already eligible for the Nevada RPS, and expanding eligibility to these new sources is not likely to substantially alleviate the compliance difficulties faced by the Nevada utilities.

\section{Allow Unbundled Renewable Energy Credits From Other States As Long as Reciprocity is Allowed (and States Have a Comparable RPS)}

Some states only allow out-of-state renewable energy credits or generation if the exporting state allows renewable energy generation or credits from the importing state, or going further, also have a comparable RPS. Such conditions are called "reciprocity". Most of the states surrounding Nevada that have RPS policies have relatively stringent conditions governing 
eligibility of out-of-state renewable energy, and it was not clear that Nevada would benefit from such a reciprocity arrangement. That said, reciprocity might be an attractive component of the $15 \%$ proposal noted above.

\section{Maintain Current Nevada RPS Restrictions for Out-of-State Renewable Energy}

Some workshop participants did not favor easing the out-of-state restrictions for the Nevada RPS, arguing that the economic development and environment benefits of the existing restrictions are warranted. However, the restrictions are strict enough, and RPS non-compliance is pervasive enough, that some relaxation may be warranted, as described earlier.

\section{Renewable Energy Set-Aside As Condition for Transmission Upgrades for New Fossil Plants}

At least three coal plants and one natural gas plant are being proposed in Nevada, and some of them may require major transmission upgrades to be interconnected. This opens the possibility of requiring that a set-aside for renewable energy on the transmission line be imposed as a permit conditions for the fossil fuel plant. However, the PUCN does not have jurisdiction in Washoe County, where one of the proposed coal plants would be sited. In addition, nothing prevents renewable energy developers from working with one of the fossil plant developers to access transmission. Finally, generator interconnection and transmission access are generally under FERC jurisdiction, and it is not clear that Nevada a could impose transmission conditions as part of granting a permit.

\section{Rolling Over RPS Shortfalls to Future Years}

Under this option, Nevada utilities could delay complying with the Nevada RPS but would have to roll over the shortfall into future years as "make-up" compliance. However, this option does address the root causes of RPS non-compliance, and instead only delays compliance. The authors believe that the application of a well-designed ACM mechanism is a better option for Nevada at this time. 
APPENDIX B 


\section{Appendix B - Options Not Considered}

The options listed below were identified by workshop participants, but were not considered further as priorities because workshop participant voting indicated these were less important than options discussed earlier.

\section{If PUC Levies Financial Penalties for RPS Non-Compliance, Use Proceeds for Renewable Energy Projects}

As noted earlier, the PUCN can penalize Nevada utilities at least the difference in cost between the market price of renewable energy generation and market prices for electricity for not complying with the Nevada RPS, and Nevada utilities are not allowed to recover such penalties from ratepayers. This option would devote any proceeds from penalty payments for the development of renewable energy generation. Because the Nevada utilities have some credit issues, a penalty for RPS non-compliance may only aggravate these issues and could lead to legal action by the Nevada utilities. Removing the waiver, allowing Nevada utilities recovery of ACM payments under certain circumstances, and devoting ACM proceeds to renewable energy development would accomplish the aims of this option without endangering the credit of the Nevada utilities.

\section{Clarify that PTC Ownership Stays with the Generator}

At the workshop, some renewable energy companies said the issue of who receives the production tax credit has come up during contract negotiations, and asked that the PUCN or the Nevada Legislature decide this issue in favor of the generator. Because the PTC is a federal tax incentive, neither the PUCN nor the Nevada Legislature has any authority to take action on this issue.

\section{Apply a Penalty for Failed Projects}

Penalties would be applied (to either the utility or the generator) if a renewable energy project fails to become operational, thus hopefully encouraging Nevada utilities to vigorously pursue RPS compliance. These arrangements are best left contractually between the renewable energy generator and Nevada utilities. As mentioned before, the ACM mechanism may accomplish the same goals but without the punitive nature of a penalty upon the utilities, and a penalty placed upon contracted generators who fail to meet milestones is already considered in the earlier recommendation to improve the procurement process.

\section{Expand or Alter Universal Energy Charge to Include Renewable Energy}

Nevada has a universal energy charge (UEC) to assist low-income customers in paying their energy bills. At the workshop, some suggested expanding the UEC to include renewable energy, but it was acknowledged this is politically risky. For that reason, this option was not considered as a high priority item. 


\section{Include Energy Efficiency in the Nevada RPS}

Some stakeholders support including energy efficiency as an eligible technology for the Nevada RPS. This raises several challenging issues that were not discussed fully at the workshop, such as how to measure energy efficiency reductions in an equally rigorous manner as generation, and how to determine the baseline for qualifying energy efficiency reductions (free riders are a major risk to fairly applying eligibility for energy efficiency under an RPS. For these reasons, and also because the Nevada RPS has an expansive list of eligible renewable energy technologies, this option was not considered a high priority item as this time. While energy efficiency policy should be considered in Nevada, the authors believe that such policy should not be directly linked to the existing RPS.

\section{Include Waste-to-Energy as an Eligible Technology for the Nevada RPS}

There was some support at the workshop for including waste-to-energy as an eligible technology for the Nevada RPS. Because technology eligibility for the Nevada RPS is quite broad already, this option was not considered as a high priority item at this time.

\section{Address Federal Agency Permitting Barriers Toward Siting New Transmission}

Neither the Nevada Legislature nor the PUCN can address this issue, so this option was not considered further.

\footnotetext{
Allow RPS Waivers Three Times and Then Apply Penalties ("Three Strikes")

For this option, Nevada utilities would be allowed three waivers from complying with the Nevada RPS before penalties would be imposed. Because compliance with the Nevada RPS may not occur immediately, Nevada utilities may use up their three waivers quickly. Also, as noted before, the penalties in the statute are not specified. For these reasons, the ACM mechanism was preferred.
} 
APPENDIX C 


\section{Are actions required to support the $5 \%$ solar component of the RPS?}

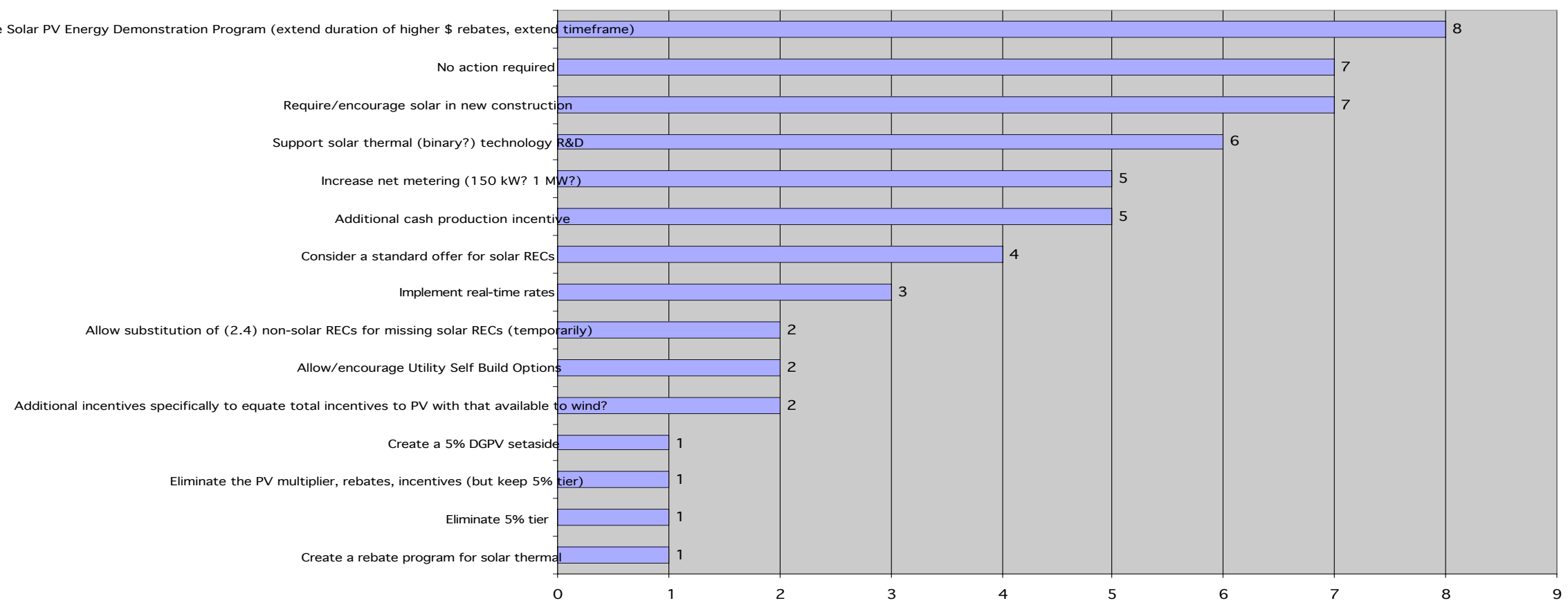




\section{What if any changes to enforcement or incentive mechanisms improve the RPS?}

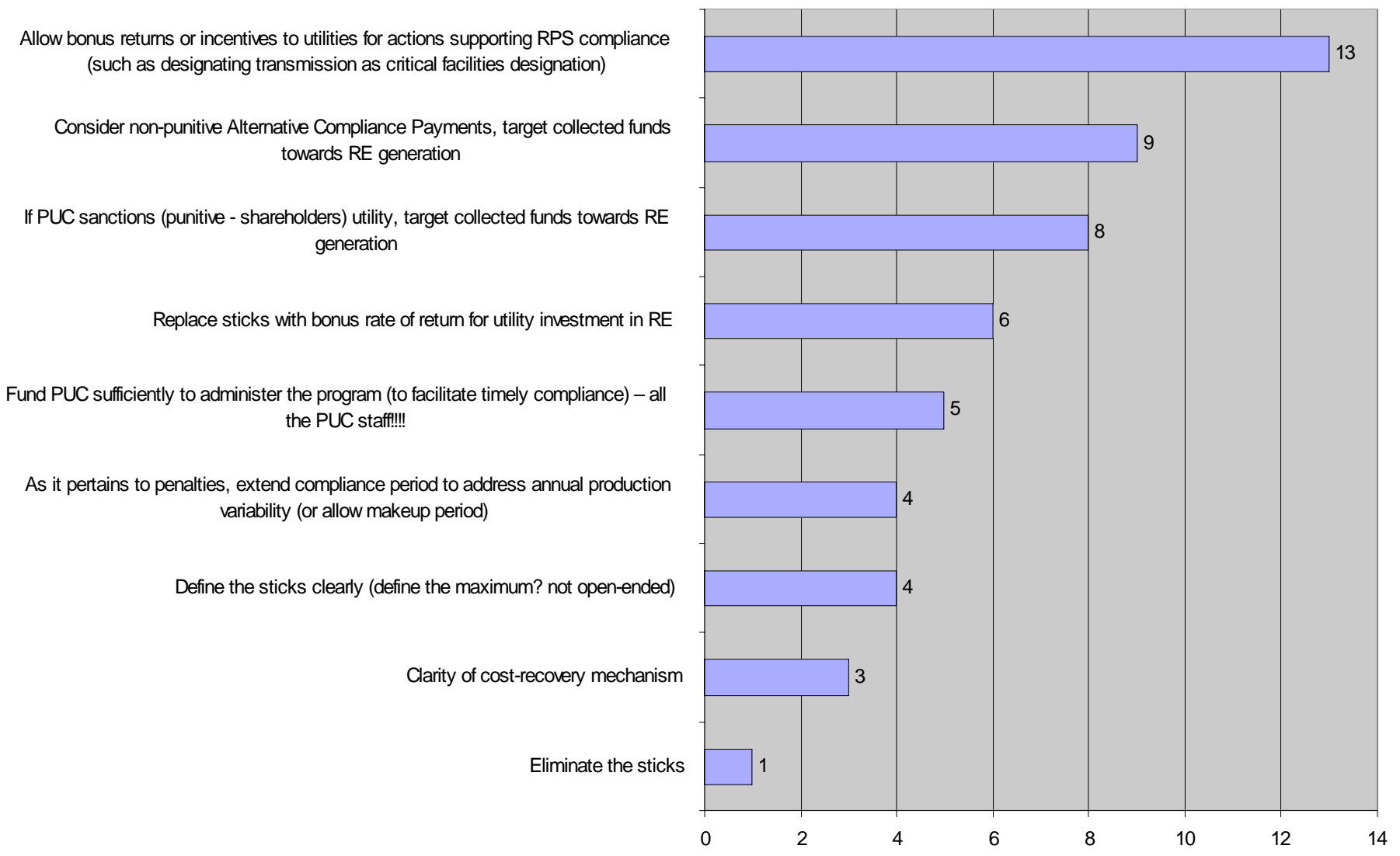




\section{Would changes to the utility RE solicitations improve compliance?}

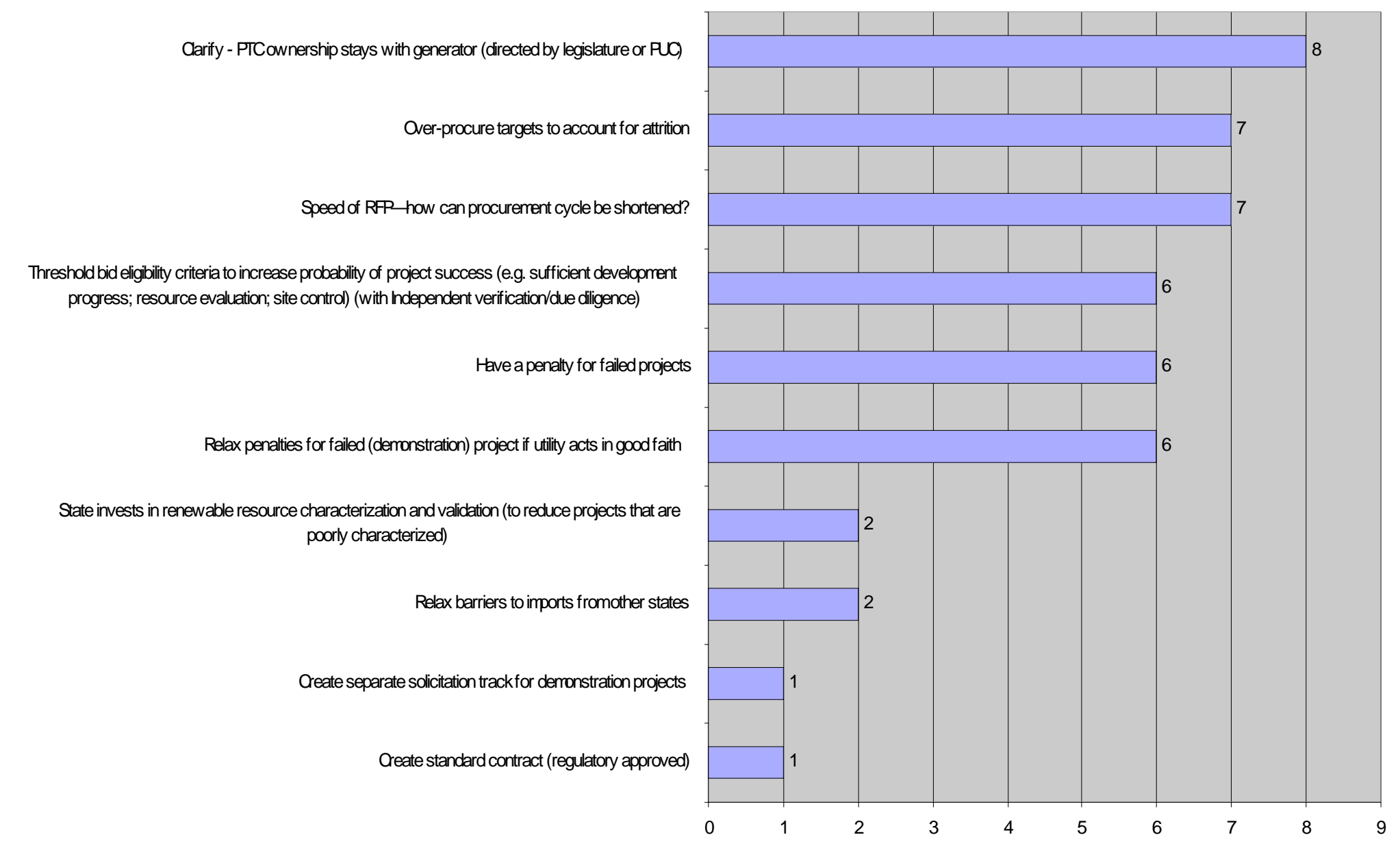




\section{Are any additional changes necessary to ensure financing of RE projects?}

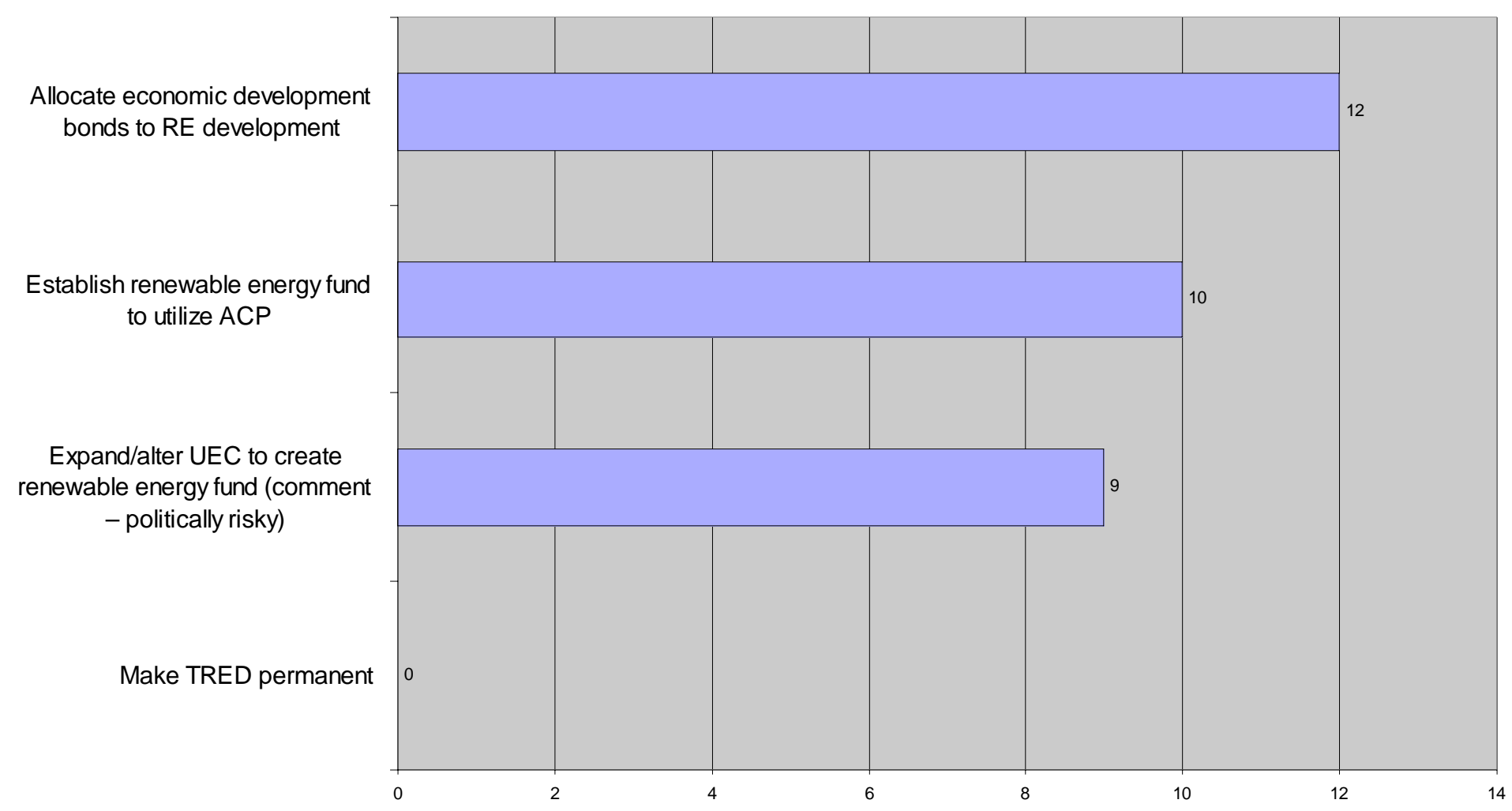


Are expansions of RPS eligibility to other resources besides renewable resources warranted, or consistent with stated policy objectives?

Energy efficiency (not CLM) - demonstrate permanent savings (w hy? Help utility meet RPS from bigger pool; and will reduce the cost) (w hy not? Keep supply distinct from demand; apples \& oranges)

Passive solar (e.g. daylighting) - address in regulation

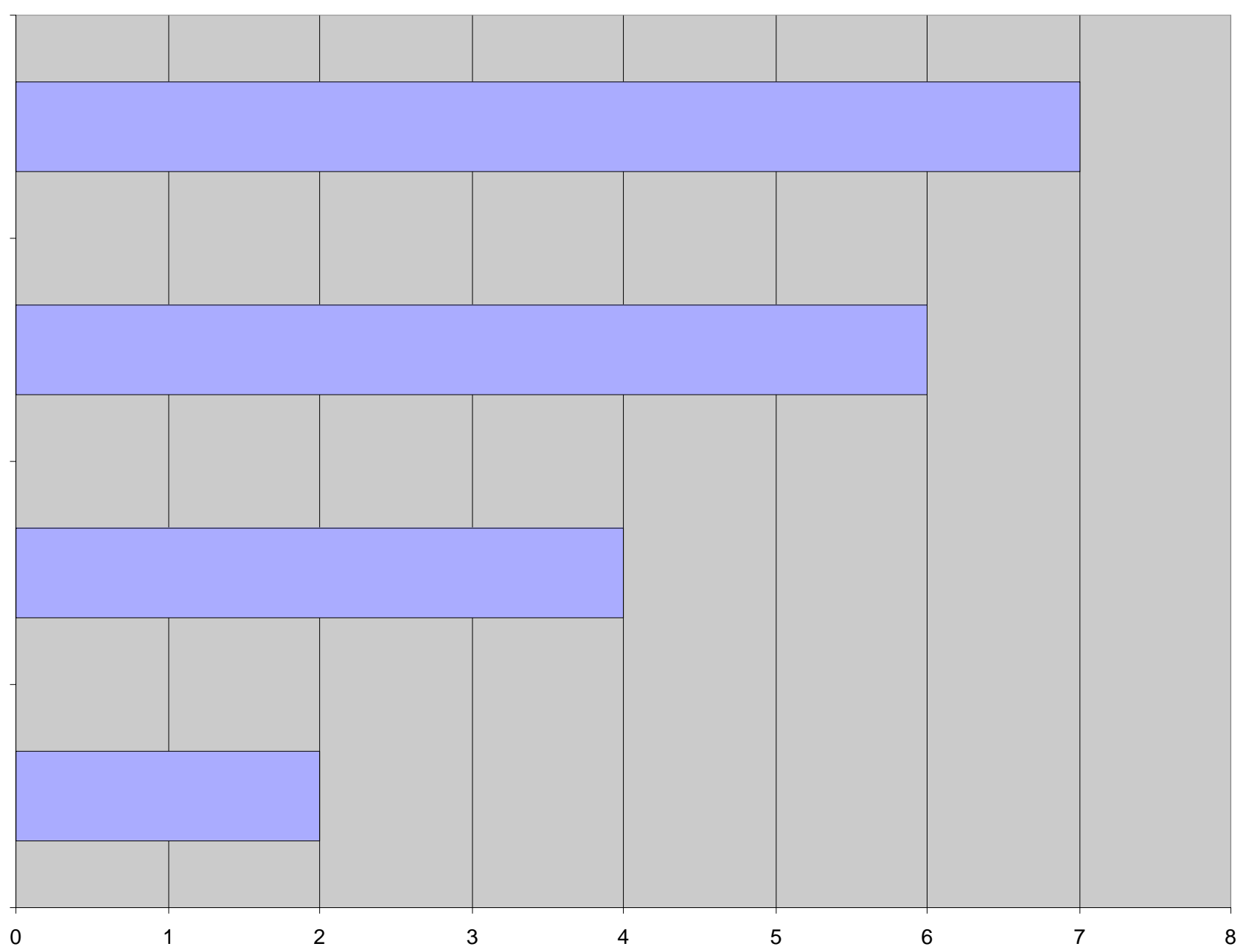




\section{Are changes to RPS renewable resource eligibility warranted, or consistent with stated policy objectives?}

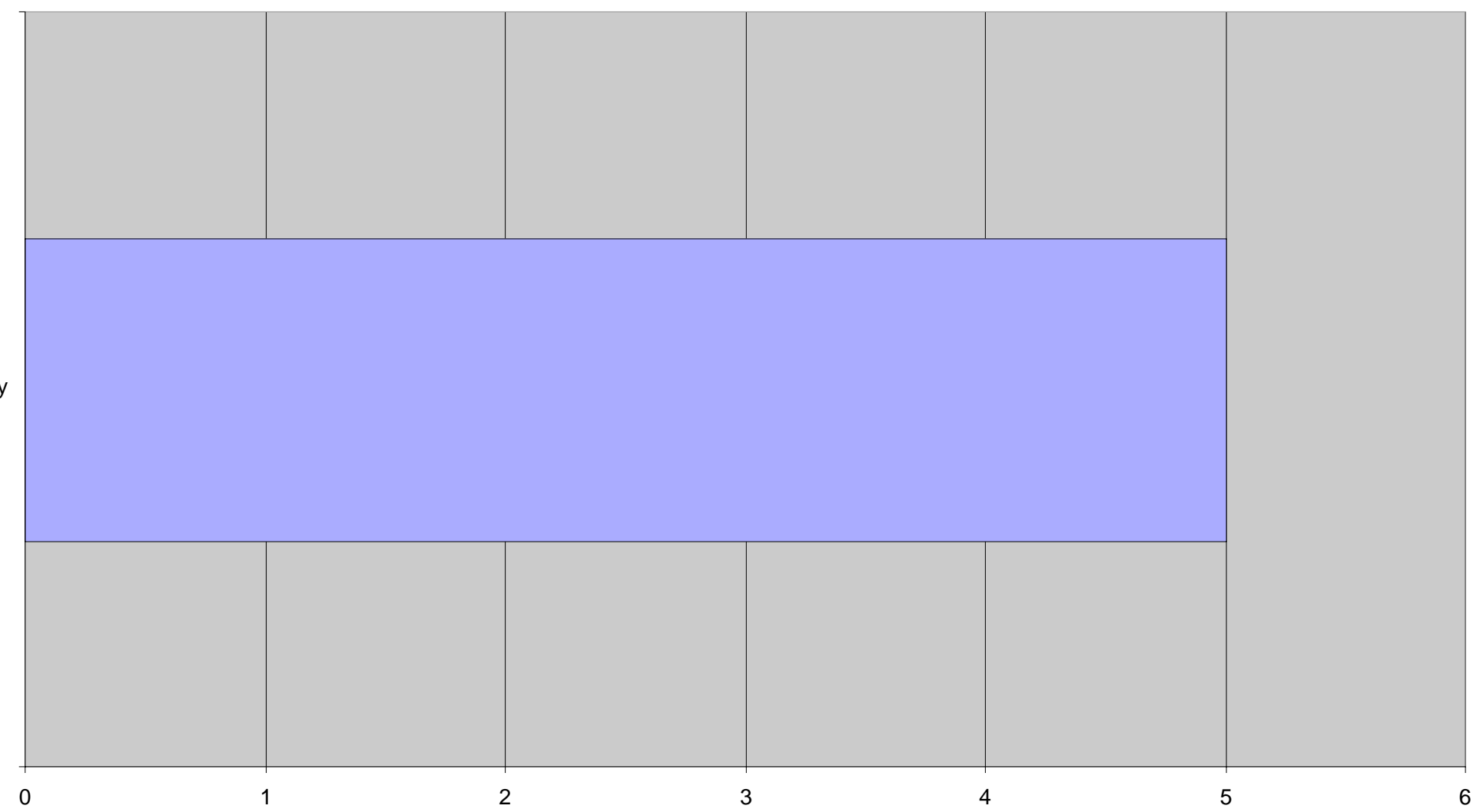




\section{Imports Recap: Policy Options to Consider}

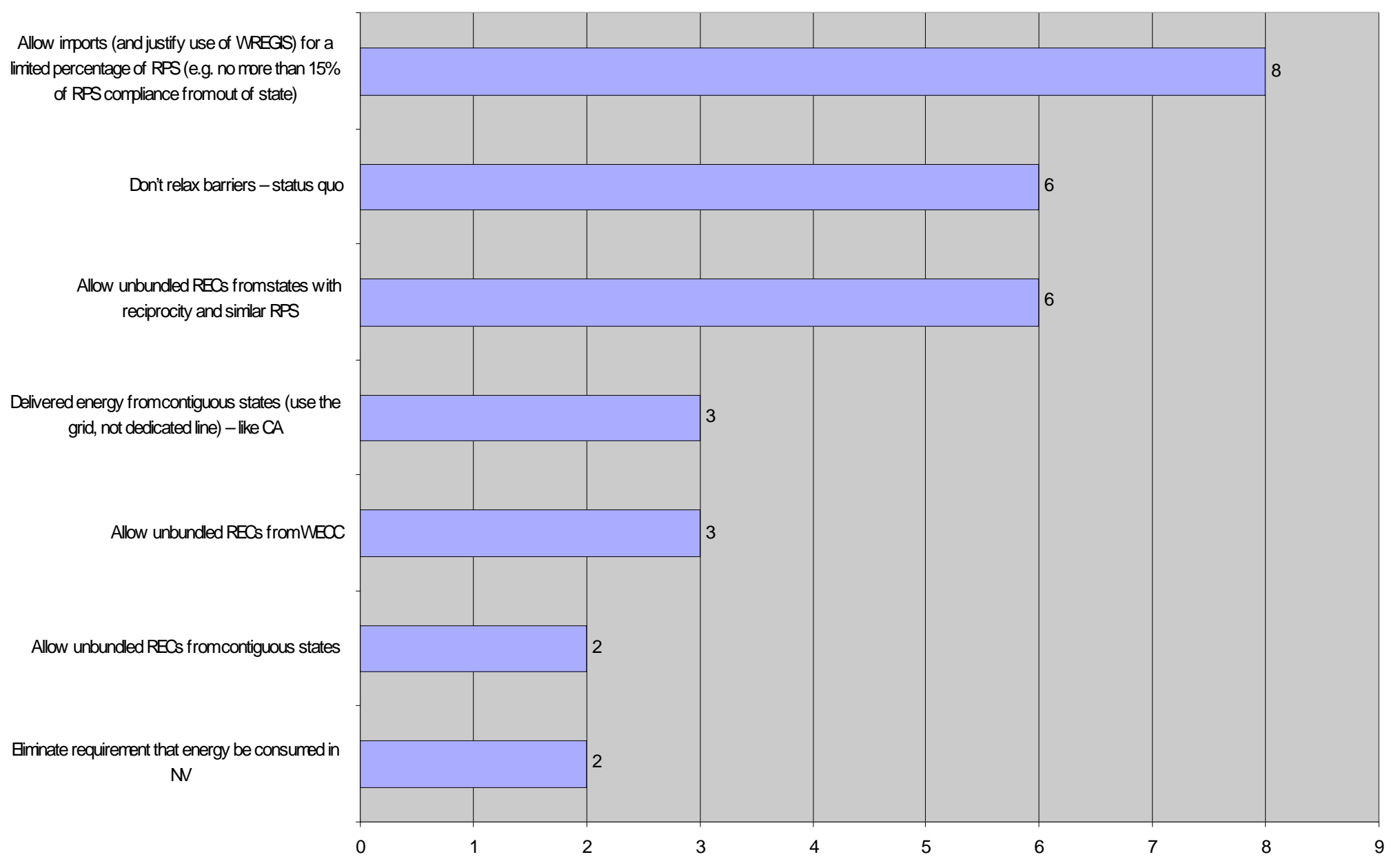




\section{WREGIS Recap: Policy Options to Consider}

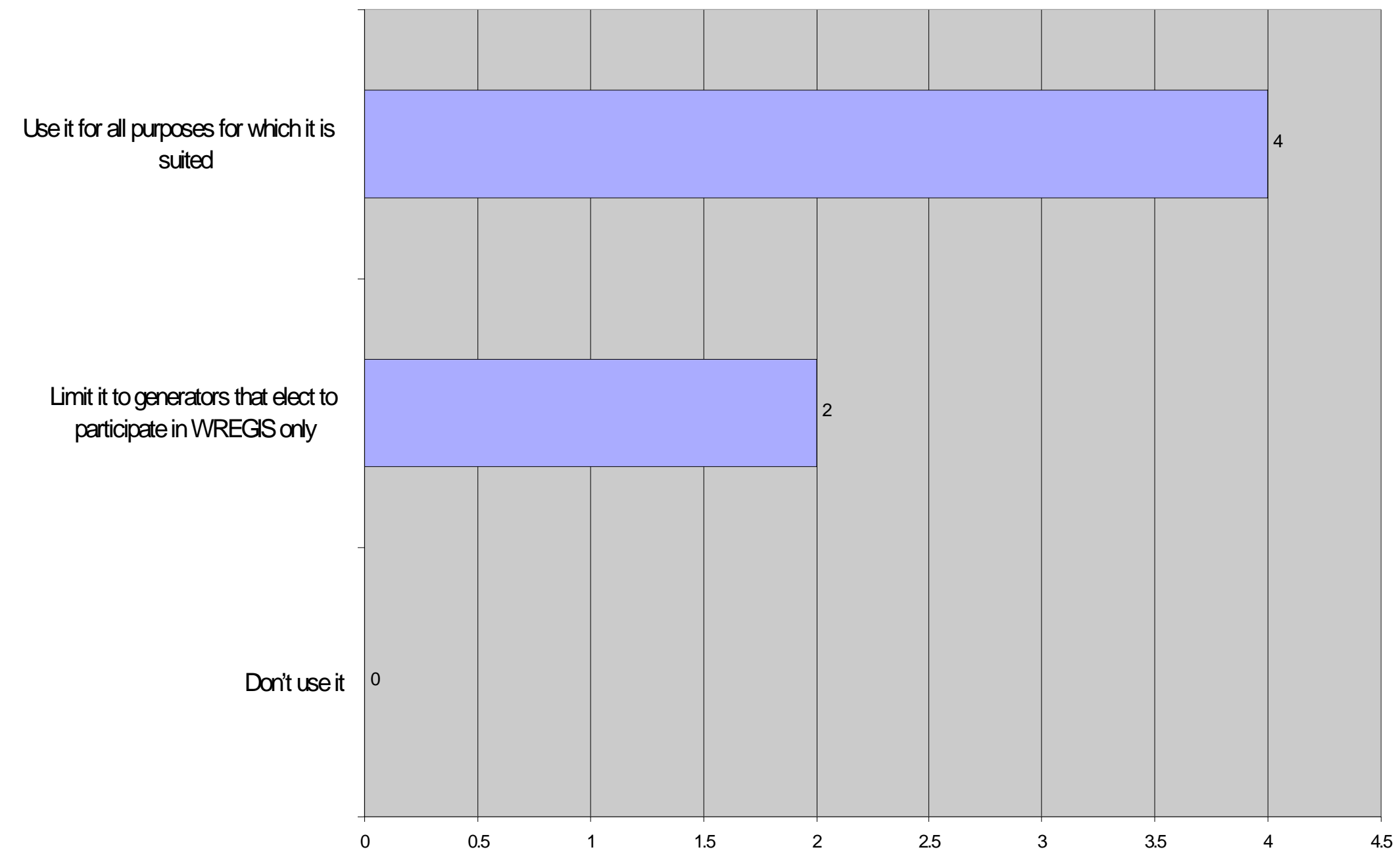




\section{Transmission Recap: Policy Options to Consider}

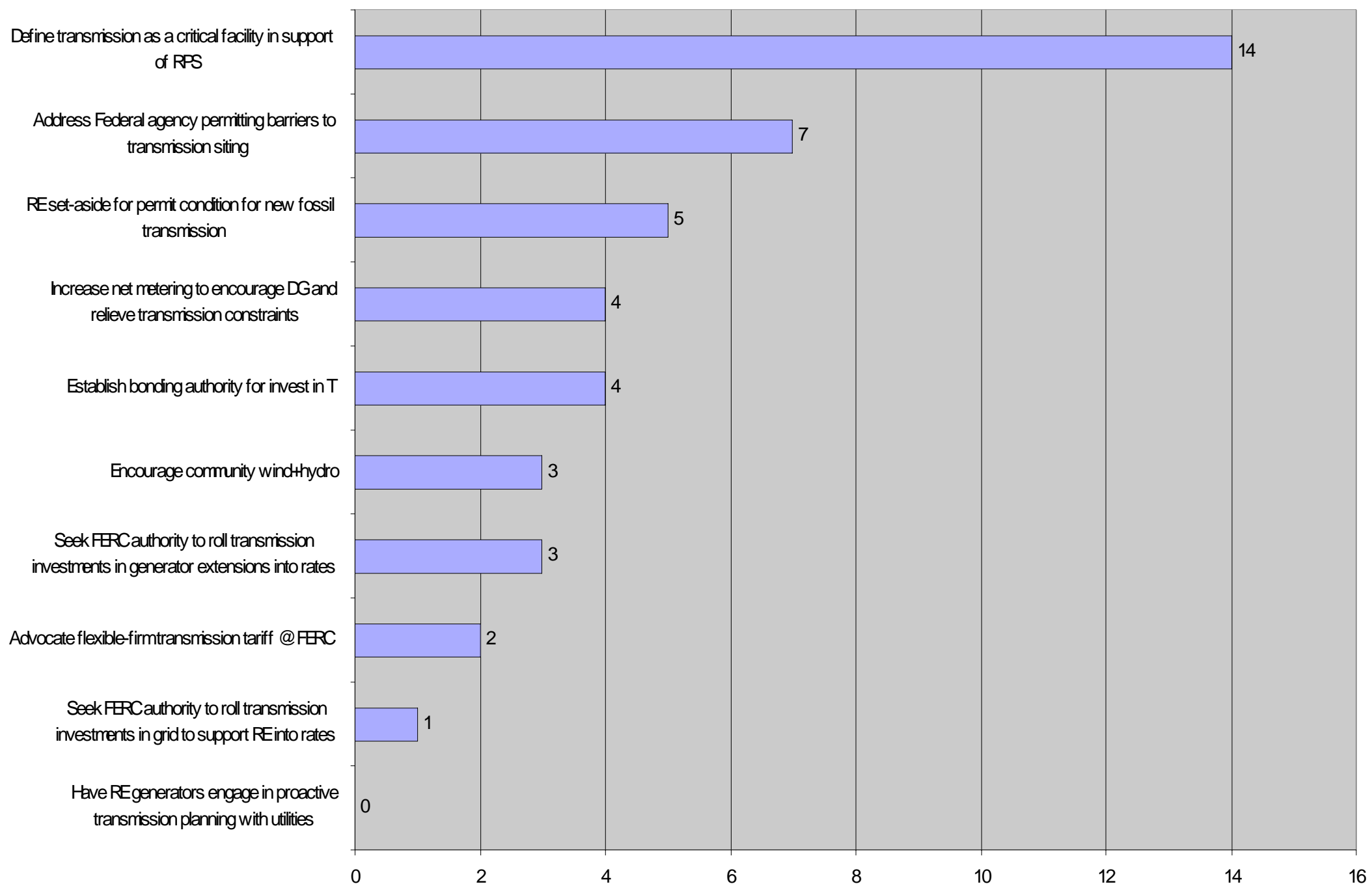




\section{How can/should future RPS targets be adjusted to account for failed contracts?}

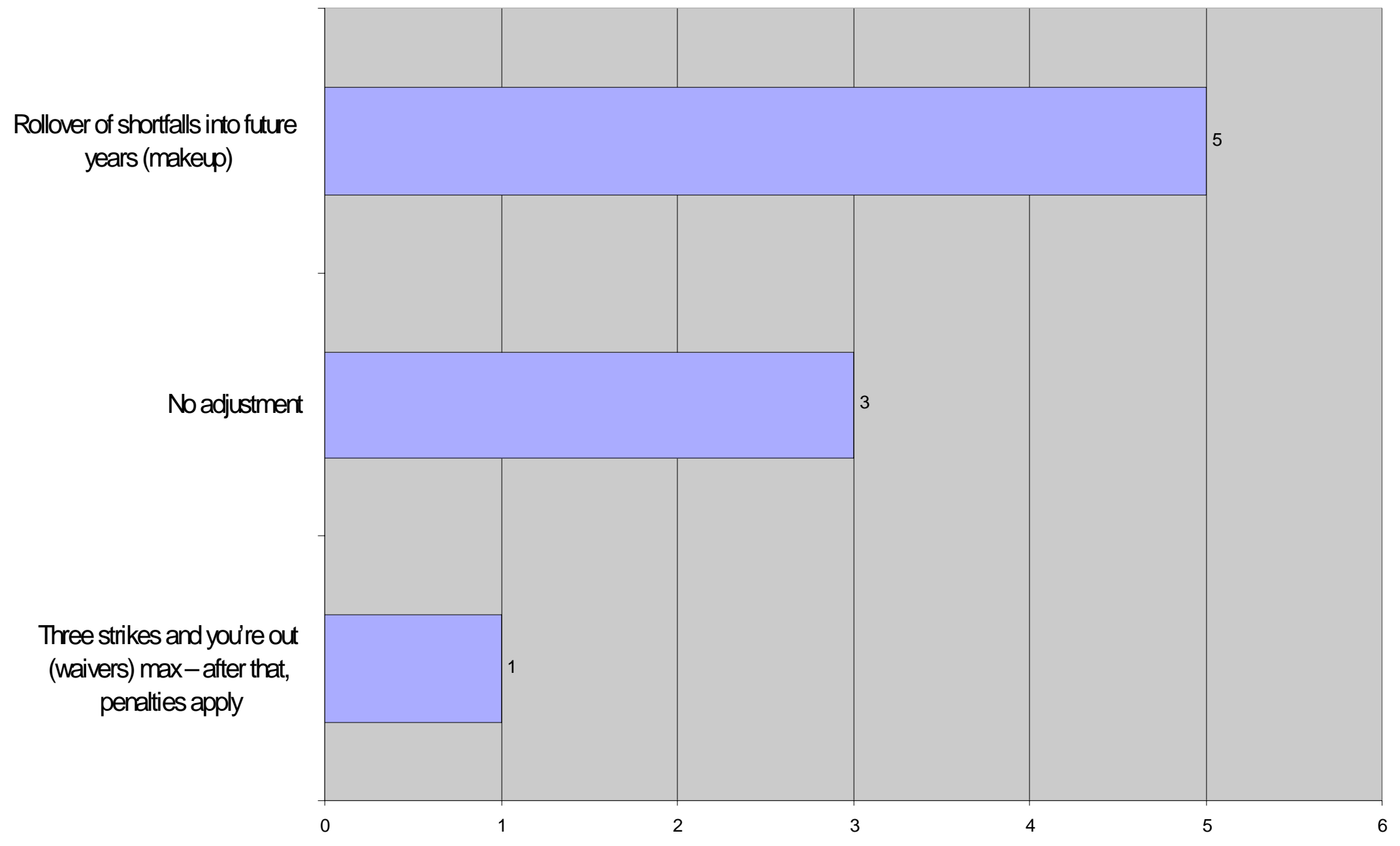




\section{How to incorporate demonstration technologies?}

Pressure letdown or waste heat recovery -- How to demonstrate new technologies?

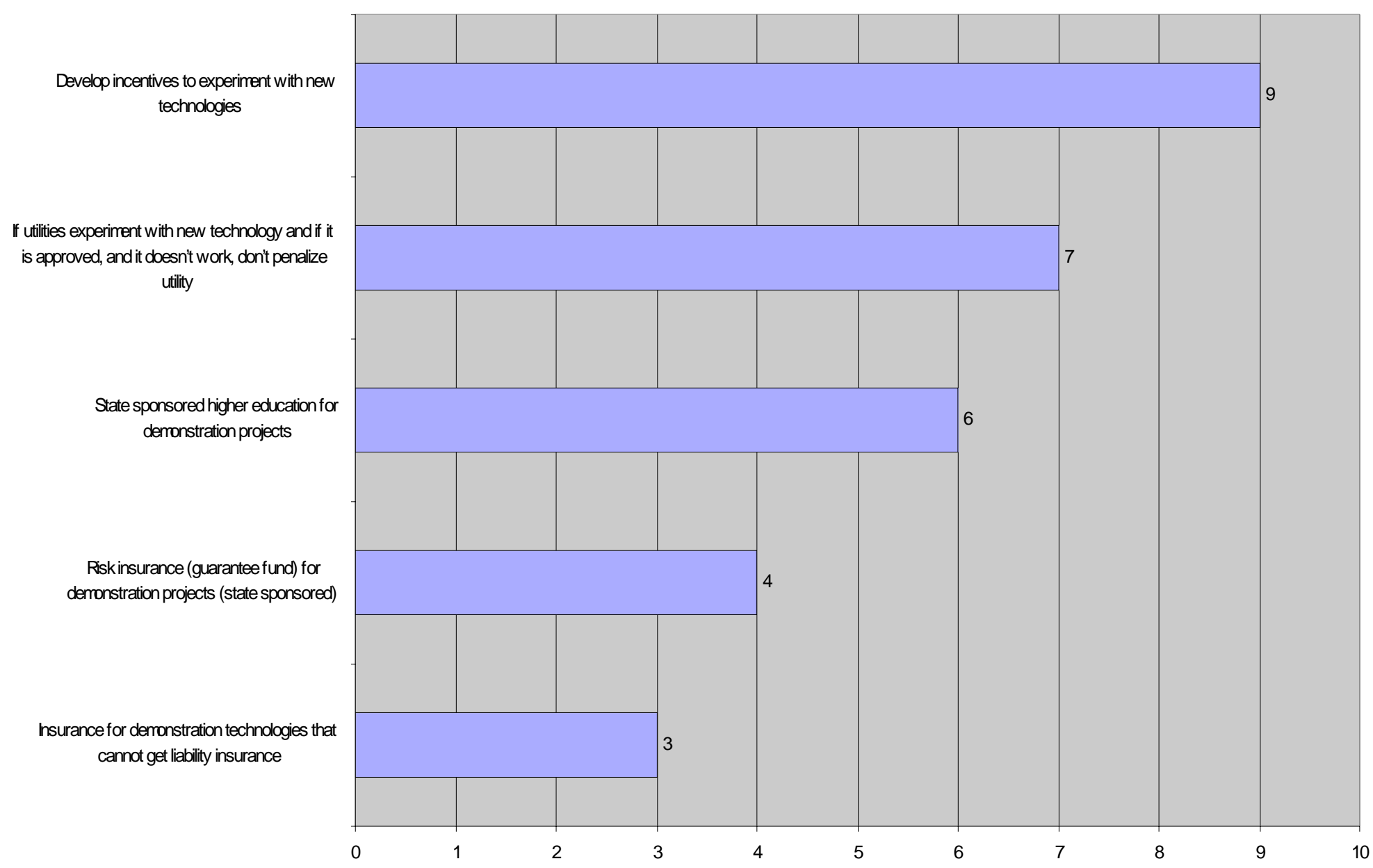

